\author{
Joanna Dzionek-Kozłowska \\ University of Lodz \\ e-mail: joanna.dzionek@uni.lodz.pl \\ ORCID: 0000-0003-2146-5491

\section{Jarosław Neneman} \\ University of Lodz \\ e-mail: jaroslaw.neneman@uni.lodz.pl \\ ORCID: 0000-0003-0865-4706
}

\title{
EDUCATED OR INDOCTRINATED? REMARKS ON THE INFLUENCE OF ECONOMIC TEACHING ON STUDENTS' ATTITUDES BASED ON EVIDENCE FROM THE PUBLIC GOOD GAME EXPERIMENT
}

\begin{abstract}
Economic education is frequently blamed for negatively affecting students' values and attitudes. Economists are reported as less cooperative, more self-interested, and more prone to free-riding. However, empirical evidence is inconclusive - certain studies support while others gainsay the socalled indoctrination hypothesis. We contribute to the discussion by running a Public Good Game (PGG) quasi-experiment. Working with economics and non-economics graduates $(\mathrm{N}=206)$, we compared contributions to the common fund by representatives of both subsamples. Students' contributions were then juxtaposed against the scores they achieved from the exam items, testing their command of game theory to detect the supposed influence of economic teaching. We hypothesised that holders of a bachelor's degree in economics and management would contribute less to finance the common good. We also expected that those whose exam scores were higher would donate less to the common fund in the PGG. Contrary to expectations and prior empirical evidence, students holding a bachelor's degree in economics and management made higher contributions to the common fund than their non-economics counterparts. Also, we found no correlation between the level of donations and exam scores. We conclude that there are no grounds for considering economic teaching as promoting uncooperativeness and exerting the supposed harmful influence on students' character. We claim that economic departments provide education rather than indoctrination.
\end{abstract}

Keywords: Public Good Game, economic education, indoctrination hypothesis, quasi-experiment. 


\section{Introduction}

Economics students and alumni are frequently presented as different from those who have chosen other academic majors. Numerous studies have reported economists as more egoistic (Frank, Gilovich \& Regan, 1993; Mertins \& Warning, 2014; Krick et al., 2016), greedy (Wang, Malhotra \& Murnighan, 2011), profit-oriented (Frank \& Schultze, 2000; Rubinstein 2006), and dishonest (O'Clock \& Okleshen, 1993; Frank \& Schulze, 2000), while also being less cooperative (Marwell \& Ames, 1981; Cadsby \& Maynes, 1998; Dzionek-Kozlowska \& Rehman, 2017a), less generous (Kahneman, Knetsch \& Thaler, 1986; Bauman \& Rose, 2011), and even less morally sensitive (Krick et al., 2016). The roots of those differences are found in either nurture (economics and business teaching) or nature (the supposition that economic and business studies are taken up by people who already have the above-mentioned anti-social attitudes and personality traits). The first approach leads to discussing the so-called indoctrination hypothesis. ${ }^{1}$ The second one results in examining the selection hypothesis.

One of the methods repeatedly taken to investigate the differences and similarities between economists-to-be and other students consists in conducting experiments grounded on game theory. Fairness and generosity are commonly analysed by scrutinising decisions students make in the Ultimatum and similar games, where as cooperativeness and communitymindedness are examined with the Prisoner's Dilemma, the Public Good, and other non-cooperative games. The so-called Trust Games are constructed to pick up disparities in trust, honesty, and truthfulness.

The present study contributes to the debate on the influence of economic education on students' attitudes and values by pointing out certain shortcomings of concluding about economists' peculiarity derived from experiments based on game theory. Our arguments are grounded on empirical evidence gathered at one of the major public universities in Poland. Working with a sample of first-year graduates holding a variety of bachelor's degrees $(\mathrm{N}=206)$ who were enrolled in a two-year master's programme in Business Management, we scrutinised choices they made in a Public Good Game (PGG). This step let us examine whether their choices revealed "indoctrination" by their undergraduate education. As the second step, we juxtaposed the students' decisions in the PGG against the scores they achieved from the exam items testing their command of game theory. Drawing from earlier research (e.g., Marwell \& Ames, 1981; Frank, Gilovich \& Regan, 1993; Seguino, Stevens \& Lutz 1996; Cadsby \& Maynes, 1998; Lanteri \& Rizzello, 2007; Kaiser, Pedersen \& Koch, 2018), we hypothesised that holders of a bachelor's degree in economics and management would con- 
tribute less to finance the public good. We also expected that those whose exam scores were higher would donate less to the common fund in the PGG. Such a supposition was based on interpreting the higher scores as a sign of a deeper understanding of premises and consequences of strategies possible to choose in economic games and an awareness that game theory regards a lower contribution (or no contribution at all) as a rational choice in the PGG.

To our surprise, and contrary to expectations and prior empirical evidence, students holding a bachelor's degree in economics and management made higher contributions to the common fund than their non-economics counterparts. Moreover, the analysis of their comments revealed that at least some of them were well aware their choice violated what game theory suggests as a reasonable course of action. Yet, for the sake of values that differ from the simple need to maximize payoffs, they would have liked to contribute more anyway. These findings allow us to conclude that economic education per se is not powerful enough to significantly shake students' morality and transform them into egoistic, uncooperative, two-legged calculating machines.

This conclusion is strengthened by the analysis of a relationship between the students' exam scores and their level of donations in the PGG. We found no correlation between these two variables in the subsample composed of the holders of a bachelor's degree in economics and management who were already acquainted with the basics of game theory. Yet, we have observed a weak negative correlation in the group of non-economics bachelor's degree holders. This outcome can be seen as a short-term side effect of economic education (in particular, students first meeting with game theory). However, there are no grounds for regarding this education as economic "indoctrination" or as something that would significantly shake the students' mindsets and systems of values.

The line of reasoning pursued in this article starts with a review of empirical studies on the effects of economic education on students and alumni. We then move to report on our present research and compare our results to the evidence provided by other scholars. The final section both summarises and concludes our findings.

\section{Literature review}

Certain remarks about economics students specific characteristics were passed as early as the first university programmes in economics were offered (cf. Marshall 1920/1890, 4-5). However, the discussion regarding the in- 
fluence of economic education on those who decided to choose economics as their major was invigorated forty years ago by Maxwell and Ames (1981) as a by-product of their investigations on free-riding in financing public goods. After conducting eleven experiments within various frameworks and with various groups of participants, they noticed that in all but one group the average level of contributions to a common good was significantly higher than what might have been expected according to game theory rationale. The distinct group donating considerably less than the others was a batch of economics majors. This finding was announced in the title of their paper Economists free ride, does anyone else? (1981), the publication of which opened a debate leading towards a stream of empirical research inquiring economists' peculiarity and its roots.

Economists' sense of fairness was examined by Kahneman, Knetsch and Thaler (1986) and Carter and Irons (1991). Both teams of scholars employed the Ultimatum bargaining game to detect differences between choices made by business and economics students and the non-economics cohorts of respondents. Disparities were noticed in both studies. Carter and Irons interpreted them in accordance with the selection hypothesis.

The discrepancy between economists and non-economists was confirmed by Frank, Gilovich and Regan (1993), who analysed students' decisions in the Prisoner Dilemma game. The rate of defection was higher for the economists. Interestingly, the authors also reported that the rate of cooperation increased and the difference between both groups nearly disappeared when respondents were allowed to communicate before making decisions about their strategies. ${ }^{2}$ In addition, they noticed that (1) females tend to cooperate more often than males, and (2) the defection rate decreased with the advancement of students' academic education. The first of those findings was strongly supported by Seguino, Stevens and Lutz (1996), who investigated respondents with a simplified version of the Maxwell and Ames' (1981) PGG. However, the second one was called into question. In contrast to Frank, Gilovich and Regan, Seguino, Stevens and Lutz observed the defection rate to increase with the growing number of economics courses completed. As a result, they advocated for the indoctrination hypothesis.

New points to the debate were added by Cadsby and Maynes (1998), who contrasted economists and nurses. They worked with a PGG with a threshold with two Nash equilibria: cooperative and non-cooperative. The game was structured in such a way to award groups managing to reach the threshold and to "punish" groups unsuccessful in doing so (i.e., when a threshold was not reached, all the tokens invested by 
the group members were lost). No communication between the respondents was allowed. In the course of twenty-five repetitions of the game, nurses gravitated towards the cooperative equilibrium, whereas economists moved towards the non-cooperative one. Counter-intuitively, it was not economists but nurses who became much more successful and "richer" towards the end of the game. Cadsby and Maynes showed polarity between both groups, although they did not adopt a position in a debate on nature vs nurture.

The contrast between economists and nurses was confirmed by Lanteri and Rizzello (2007), yet this time with empirical evidence from a Prisoner's Dilemma game experiment. Students of economics not only defected more often than nurses and lawyers (who constituted the third group of respondents in that research) but also expected others to defect more frequently. Untrusting because of the public image of economists, both nurses and lawyers chose uncooperative strategy more commonly when they believed they were playing against an economist.

The Prisoner's Dilemma and the Stag Hunt games were employed by Ahmed (2008), who intended to examine dissimilarities between Swedish students of economics, students of humanities, and police school cadets. The latter group was chosen because in the cadets' training, benefits of cooperation were repeatedly demonstrated and a cooperative attitude was strongly encouraged. Regardless of not finding statistically significant differences between the subsamples, Ahmed observed that the economists chose cooperation less frequently than the others, with a difference of more than 15 percentage points between their results and the results of the two remaining groups. He did not find support for the indoctrination hypothesis; again, however, the share of seniors who chose cooperation was 17 p.p. lower in comparison to junior students of economics.

Lack of significant differences between economics and non-economists in contributing to a public fund was also reported by Altenmeyer-Bartscher et al. (2017), who undertook a three-phase PGG lab experiment. The study was formulated to determine respondents' readiness to pay for an institution (a communication platform) designed to overcome the free-riding problem. Both groups had difficulties reaching the threshold needed to "pay" for communication, yet economists contributed significantly more when the rules of the game were modified to make the game more investment-friendly (players did not lose resources invested to pay for the communication platform unless they reach the threshold needed to finance it). Economists turned out to be more adaptable and responsive to the institutional economic incentives. 
Statistically significant differences between economists and non-economists were also found by Wang, Malhotra and Murninghan (2011), Gerlach (2017), and Kaiser, Pedersen and Koch (2018), who observed students playing games based on the Dictator scheme. Wang, Malhotra and Murninghan used the simplified version of this game with only two possible options: 50/50 and 9.25/0.75. Gerlach introduced a third player, who acted as a judge and was able to pay to veto the split offered by a proposer. Finally, Kaiser, Pedersen and Koch constructed a social dilemma game that included possible punishment for the free-rider. Respondents were faced with a task to finance a public good playing in a four-person group. They were asked to imagine that three players decided to contribute all their resources to the common fund while the fourth person free-rode. The question was if they would like to give away one-tenth of the initial resources to punish the free-rider. In all Dictator-based experiments, students of economics divided their resources less equally, keeping higher sums for themselves. Yet, they also expected to receive less and vetoed the proposed split less often than the other students. There were no statistically significant differences between the economists' and the other students' willingness to punish the non-cooperative behaviour. These findings were interpreted as a sign of economists' greed, although their higher eagerness to punish non-cooperativeness was not detected.

The evidence collected with the sequential trust games by Dasgupta and Menon (2011) and Haucap and Müller (2014) led them to conclude that economists are both less trusting and less trustworthy. The most striking outcome stemming from the former study was as follows: faced with the "trusting" strategy of the other player, only $25 \%$ of the economists reciprocated, whereas reciprocity was chosen by $61 \%$ of the non-economists. Haucap and Müller (2014) found that economists become less and less trusting over the course of their economic education; a conclusion that supports the indoctrination hypothesis.

A decrease in trust after exposure to economic teaching was also reported by Xin and Liu (2013), although their study was not intended to compare economics and non-economics students. Those authors were focused on short-term effects observed in participants whose fields of study were unspecified. The same approach was taken by Ifcher and Zarghamee (2018). Both pieces of research reported respondents' decisions changed after a meeting with economic content. Xin and Liu noticed the decreasing trust of participants playing two rounds of a sequential trust game after reading a brief description of the homo oeconomicus model, ${ }^{3}$ whereas Ifcher and Zarghamee checked respondents' decisions in four types of standard eco- 
nomic games (the Ultimatum, the Dictator, the Prisoner's Dilemma, and the PGG) after the respondents became acquainted with a short text dedicated to game theory. The basics of game theory presented in a normative way, i.e., written as a guide explaining how to play to "win", ${ }^{4}$ caused participants to choose strategies regarded as rational by game theory in almost all the cases.

Another dimension was added to the discussion by James, Soroka and Benjafield (2001). They turned back to the Ultimatum Game to compare their results to outcomes received earlier by Carter and Irons (1991). The former team investigated Canadian students while the latter worked with Americans. Comparison of evidence collected in both studies revealed significant differences between the two samples. Canadians split the available resources much more equally than Americans. This finding cast some doubt on whether economic education is a key determinant of students' performance in economic games. A similar conclusion came from an experiment that Iida and Oda (2011) conducted in Japan. Admittedly, the authors reported that Japanese students of economics cooperated less often in the Prisoner's Dilemma game than non-economists. However, the difference was statistically irrelevant. Considering evidence gathered in many Western countries (where, as it was already mentioned, the rate of defection for economists was repeatedly higher than in the case of other students), Iida and Oda concluded their result might have been triggered by a less individualistic corporate culture and a higher emphasis put on cooperation by Japanese society. Hence, we can conclude that culture may considerably modify or even play a dominant role in shaping students' choices in economics games. ${ }^{5}$

More serious doubts about making conclusions about economics and business students' attitudes and character traits from decisions they make in games were aroused by scholars working with other research tools. Studies based on surveys concerning values and ethical orientations sporadically revealed the alleged differences between economists and non-economists (cf. e.g., Delgado et al., 2020; Dzionek-Kozłowska \& Rehman, 2019; Hummel, Pfaff \& Rost, 2018; Krick et al., 2016; Neubaum et al., 2009; Tse $\& \mathrm{Au}, 1997)$. Yet, the greatest challenge to research grounded on games has been posed by scholars undertaking field experiments. One of the most important studies of this type was a lost-letter experiment conducted by Yezer, Goldfarb and Poppen (1996). Unsealed envelopes containing a small sum of money (10 USD) and a letter explaining that the sum was repayment of an informal loan for a person whose name and address were handwritten on the envelope were left in lecture halls occupied by students of different 
majors. Contrary to the conclusions of many researchers engaged in this discussion, Yezer, Goldfarb and Poppen found out that economists were more honest $^{6}$ than the others as they returned the letters more frequently than non-economists (the rate of return was $56 \%$ and $31 \%$, respectively).

A similar conclusion stemmed from a study conducted by Laband and Beil (1999). They checked alumni's honesty in disclosing their level of selfdeclared incomes, which were used to assign values to the yearly membership fees for three professional organisations: American Economic Association (AEA), American Political Science Association (APSA), and American Sociological Association (ASA). Considering the evidence gathered from dozens of experiments grounded in game theory, Laband and Beil reached an unexpected conclusion: professional economists were not the least but the most honest out of the three groups taken into account in their study.

Seemingly, questions regarding the influence of economic education on students' attitudes have less obvious answers than one would have imagined by looking solely at the game-theory-based research. The present study sheds some light on the roots of the inconsistency in conclusions reached with surveys, field, and lab experiments.

\section{The study}

Undertaking our research, we took the unique opportunity to examine and compare two distinct groups of students enrolled in the master's program in Business Management $(\mathrm{N}=206)$ at the University of Lodz in Poland. The first group was composed of students holding a bachelor's degree in economics and management, and the second consisted of students who held a variety of non-economics bachelor's degrees. Regardless of their previous academic background, both groups were required to take a compulsory 25-hour-course in Managerial Economics in the first semester of their master's studies. ${ }^{7}$ A vital component of the course is dedicated to the basics of game theory and its economic applications.

Being aware of those circumstances, we decided to face all the students with a Public Good Game based on an imaginary yet realistic narrative (cited in full in the next section). We analysed students' decisions and inquired as to whether their choices were driven by their major, as was frequently claimed in many previous studies. Thus, first, we intended to check if there was a difference between the level of the economics and non-economics students' contributions in the PGG. In addition, we scrutinised the types of argumentation they provided to explain their decisions and looked for ar- 
guments both related and unrelated to game theory or economic rationales in general. Second, we analysed the relationship between the students' donations in the PGG and the scores they received in the final exam in questions that checked their understanding of game theory to determine if the two variables correlated.

\subsection{Instrument and sample}

Our study was conducted in January 2021. The exam was held one day after the survey. Both the questionnaires and the exam papers were gathered online. ${ }^{8} \mathrm{~A}$ link to the questionnaire was shared with the students via the lecture chat. The questionnaires were not anonymous due to our willingness to juxtapose students' choices with their exam performance. However, students' decisions were confidential to each other.

Respondents first read the following narrative:

Due to the COVID-19 pandemic, members of our academic community have not used financial resources dedicated to international cooperation. As a result, authorities of our department decided to move some of the accessible means to didactic purposes. Imagine that thanks to that decision, we may play a game in which you can gain some of the money.

The rules of the game are as follows:

1. Each of you will be given 5 PLN which you may keep for yourself or donate to the common fund.

2. Your group will gain twice as much money as you donate, i.e., if your group collects X PLN in the common fund, you will get another X PLN from the university.

3. Then this collected and doubled amount will be equally divided between all of you, regardless of how much you have decided to donate to the common fund initially.

4. You may donate any sum of money between 0 and 5 PLN. It means you can decide not to contribute at all. Your donation cannot exceed 5 PLN.

5. Your donation is confidential; nobody will know how much you gave. How much would you like to donate to the common fund?

After reading that description, the participants were invited to explain the reasons behind their decisions. There was neither word nor character limit for their commentaries. Leaving comments was not compulsory: students could submit the questionnaires without filling in the space dedicated to their remarks.

Additionally, respondents were asked to reveal their bachelor's degree(s).

The second source of empirical evidence were students' papers from the final exam in Managerial Economics. Only the scores they received from the 
three questions intended to evaluate how well they mastered game theory were considered.

In the first phase of our research, we managed to collect 211 responses; however, the number of usable questionnaires dropped to 206 due to five people's decision not to go in for the exam. The subsample of students holding a bachelor's degree in economics or management studies totalled 122 people, whereas the group of non-economics degree holders totalled 84 people. In the first group, there were 67 students with bachelor's degrees in management and 55 with degrees in economics. The second group was much more diverse: 47 participants graduated in social sciences (in 12 disciplines as various as legal studies, pedagogy, sociology, and tourism), 29 participants studied humanities (in 8 different disciplines), and seven participants studied natural science. One person held a bachelor's degree in visual arts.

Among the 206 students, there were 147 females (71\%) and 59 males $(29 \%)$. The number of women in the non-economics group was slightly higher; however, the male/female ratio was almost identical in both subsamples, with just two percentage points difference between them.

\subsection{Results}

To our amazement, the students holding non-economics degrees contributed less to the common fund than the economics and management degree-holders. The average level of donation by the former group equalled 3.00 PLN, whereas the average contribution by the representatives of the latter subsample reached 3.23 PLN $(60 \%$ and $65 \%$ of the maximum possible contribution, respectively). Closer analysis of donations contributed by members of particular subgroups revealed another interesting finding: the highest average contribution came from economics majors, whereas the humanities and art students gave the lowest sum (on average). Table 1 . presents the outcomes for the subsamples specified in our study.

When it comes to the distribution of outcomes, it turned out that the most frequent donation amount was the whole sum possible to donate (5 PLN). Ninety-six respondents chose this option; 55 economists and 40 non-economists. The share of those who decided to donate the maximum amount was similar in both subsamples, reaching $45 \%$ and $48 \%$ respectively. Certain differences revealed themselves in the case of lowerlevel contributions. The economists were more reluctant to not contribute anything or keep more than half of the sum available to give up in their hands.

Donations' distribution for both groups is shown in Figure 1. 
Educated or Indoctrinated? Remarks on the Influence of Economic...

Table 1

Average contributions from students holding a bachelor's degree in economics and non-economic sciences

\begin{tabular}{|c|c|c|c|}
\hline Bachelor's degree & $\begin{array}{c}\text { No. } \\
\text { of students }\end{array}$ & $\begin{array}{c}\text { The average level of } \\
\text { contribution to the common } \\
\text { fund (in PLN) }\end{array}$ & SD \\
\hline Economic sciences & 122 & 3.23 & 1.86 \\
Economics & 55 & 3.31 & 1.83 \\
Management & 67 & 3.17 & 1.90 \\
\hline Non-Economics sciences & 84 & 3.00 & 2.10 \\
Social Sciences & 47 & 3.17 & 2.15 \\
Natural Sciences & 7 & 2.93 & 2.24 \\
Humanities \& Arts & 30 & 3.75 & 1.96 \\
\hline General sample & 206 & & \\
\hline
\end{tabular}

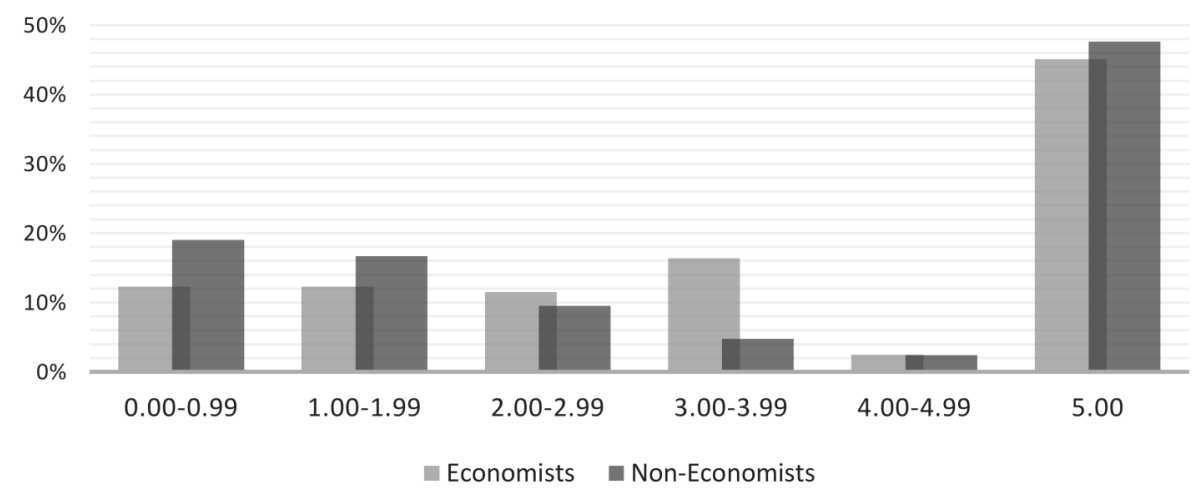

Figure 1. Distribution of donations to the common fund for economists and noneconomists (in PLN)

Considering that these outcomes were unexpected, it was fortunate that over three-fourths of respondents decided to comment on their decisions. This gave us a chance to deepen our understanding of the choices they made. Economists were more eager to share some thoughts about their picks as eighty-one percent of them left comments, whereas in the case of noneconomists only seven out of ten respondents did so. Those economists who contributed the maximum amount explained their decisions by citing a willingness to help, team spirit (playing together, enjoying the game), counting on their colleagues' cooperativeness, feeling a need to reciprocate, and fear 
of feeling remorse if the other players decided to donate more. It is noteworthy that in the group of economists there were those who revealed that they were well aware that the situation depicted in the questionnaire perfectly corresponded to the PGG scheme, and the most rational choice would be to free-ride. Regardless of recognising the theoretical pattern, however, these students decided to make a contribution. Sixteen bachelors of economics and management ( $15 \%$ of those who commented on their choices) explained that they contributed the maximum since 5 PLN is a relatively small amount. ${ }^{9}$ Four non-economists also made this comment.

We had not asked respondents' gender in the questionnaire for the sake of simplicity. However, the respondents' gender was added to the collected surveys in the data analysis phase. The study revealed that females donated a little less on average than males (3.10 and 3.22 PLN, respectively). The least generous subsample were non-economist women, while male economists contributed the most considerable sums. Yet, there was only a six percentage point gap between the two outcomes. Thus, all things considered, in our study, the differences between the subsamples of males and females turned out to be insignificant. Table 2 . demonstrates the breakdown based on gender.

\section{Table 2}

Contributions to the common fund according to the respondents' gender

\begin{tabular}{|c|c|c|}
\hline Gender & $\begin{array}{c}\text { No. } \\
\text { of students }\end{array}$ & $\begin{array}{c}\text { Average } \\
\text { contribution }\end{array}$ \\
\hline Females & 147 & 3.10 \\
Economists & 86 & 3.22 \\
Non-economists & 61 & 2.94 \\
\hline Males & 59 & 3.22 \\
Economists & 36 & 3.27 \\
Non-economists & 23 & 3.15 \\
\hline General sample & 206 & 3.14 \\
\hline
\end{tabular}

The examination of the relationship between levels of contributions in the PGG and students' scores from exam questions on game theory revealed no correlation between the two variables when the whole sample was taken into account (correlation coefficient $=-0.0969$ ). The same was true for the subsample of economists, in which case this extremely low coefficient was even lower $(-0.0465)$. However, we found a weak negative correlation 
in the non-economics group, which was noticeable especially in the case of students who studied social sciences and humanities (with correlation coefficients equalling -0.2052 and -0.1518 , respectively).

\section{Discussion and concluding remarks}

The average contribution left by respondents observed in the present research equalled $63 \%$ of the amount possible to donate, which supports conclusions drawn from many previous empirical studies (e.g., Marwell \& Ames, 1981; Cason, Saijo \& Yamato, 2002). These studies demonstrated that people usually participate in financing public goods much more than what is suggested by game theory rationales. However, our unexpected findings contradict the conclusions of some investigations that were focused on the impact of economic education.

Contrary to findings by Frank, Gilovich and Regan (1993), Seguino, Stevens and Lutz (1996), Frank and Schulze (2000), Hu and Liu (2003), Iida and Oda, 2011, Gerlach (2017), and Kaiser et al. (2018), we have not observed significant differences between decisions made by males and females. Furthermore, in our study women turned out to be less eager to contribute their resources to the common fund than their male counterparts. Surprisingly, the group contributing the most resources were male economists, while the lowest average donation came from female non-economists. However, differences based on gender were small and statistically insignificant.

In contrast with several earlier pieces of research (Marwell \& Ames, 1981; Frank, Gilovich \& Regan, 1993; Seguino, Stevens \& Lutz, 1996; Cadsby \& Maynes, 1998; Lanteri \& Rizzello, 2007), our data do not provide support for the conclusion that students of economics and business are more prone to free-riding, less eager to bear costs of financing a common good, or less cooperative. In our study, the holders of bachelor's degrees in economics and management contributed more than the other students. This difference was, however, not statistically significant.

How to explain these untypical outcomes? Considering results of studies that examine the impact of the degree of potential loss or gain on players' choices, it seems likely that the readiness of economists to donate a substantial part of their resources to the common fund can be explained by the relatively low amount of money to be given up and gained. As van den Assem, van Dolder and Thaler (2012) demonstrated in their analysis of decisions made by participants of the television game show Golden Balls, higher stakes make people less cooperative. This finding was also indirectly 
supported by the previously-mentioned Laband and Beil's (1999) research related to cheating in paying dues to professional associations. After finding in their study that professional economists turned out to be more honest than both professional political scientists and sociologists, Laband and Beil concluded that the probable reason behind such behaviour was the significantly lower level of benefits from cheating in the case of the AEA, which had the lowest fees, than the APSA and the ASA. ${ }^{10}$ Several commentaries left in the questionnaires gathered in our study provided the same argument to elucidate the students' decision to contribute to the common fund. There is, however, no good reason to claim that the low-level stakes affected the economists more than the non-economists.

Another explanation of our outcomes comes from comparing participants' exam scores with their donation levels. No correlation between these factors has revealed itself in the subsample of economists. Their comments demonstrate, however, that at least some of them consciously acted against choosing the strategy rationalized by game theory. By doing so, these students clearly showed that they were driven by motives other than the need to merely maximize payoff. We may suppose that if one is faced with a more realistic situation, not an exam task or a dry presentation of payoffs and possible strategies, we should expect the decision to be driven by much more than payoffs maximisation.

As to the weak negative correlation found in the group of non-economics bachelor's degree holders, this might indeed be read as a side-effect of economic education since those non-economists who mastered the basics of game theory decided to donate lower amounts than those whose exam grades were less satisfactory. To some extent, this effect might have been strengthened by the distribution of the survey forms during classes: regardless of the realistic narrative depicted in the questionnaire, certain students might have felt they were faced with an academic task. The question remains, however, why that effect was not observed in the subsample of those with an economics or a management degree.

We suppose that the difference might stem from the fact that for those with an economics or management degree, the course in Managerial Economics was not their first meeting with game theory. Since they were acquainted with the basics of game theory at the time of their undergraduate studies, we can assume that they had many opportunities to experience and realise differences between the abstract models of game theory and much more complex situations occurring within socio-economic reality, where more often than not many additional factors besides mere profit maximisation come into play. We may also safely assume that the vast majority 
of the non-economics bachelor's degree holders gained information about game theory no earlier than a couple of weeks preceding their participation in our research. The fact that the exam took place just one day after the survey suggests that students should have had the patterns of the economic games in their minds while filling in the questionnaire since they were going in for the exam on those issues the very next day.

Considering the results of the studies conducted by Xin and Liu (2013) and Ifcher and Zarghamee (2018), who demonstrated the short-term effect of economic teaching on respondents' choices, we may presume that the weak negative correlation between game-theory-based exam scores and the level of donations made by non-economists resulted from some of them recognising the PGG scheme in the narrative provided in our questionnaire and then answering according to game theory guidelines. Of course, some economists must have recognised the PGG scheme as well, which a number of them admitted while commenting on their choices. Yet, they apparently felt more freedom to walk away from what game theory presents as the rational decision. This, in turn, leads to the conclusion that economic teaching in general, and lecturing on game theory in particular, do not eradicate all values other than profit maximisation from students' minds. In contrast, in the long run, knowledge of economic theory doesnot seem to have a lasting effect on students' values. It is worth adding that developmental psychologists have been questioning whether it is possible to change long-held beliefs in an adult mind and substantially modify fundamental ethical values ingrained in childhood (Erikson, 1950; cf. also: Davis \& Welton, 1991). Evidence provided by Hummel, Pfaff \& Rost (2018) further proved that academic teaching does not affect students' moral development.

Considering these arguments and our findings, we conclude that game theory experiments cannot be used to draw meaningful conclusions about the influence of economic education on students' mindsets. Having worked with instruments constructed within a game theory framework, which is an important component of economic teaching, we cannot conclude anything about economists' tendencies to free-ride, their cooperativeness, their egoism, or their other traits of character. In other words, these tools, if unsupported by other methods of research, cannot help to solve the puzzle of the influence of economic teaching on students' norms and attitudes. The evidence we gathered let us conclude that there are no grounds for considering that economic teaching either reshapes students' values and norms or exerts a harmful influence on their character. Therefore, we conclude that economic departments provide education rather than indoctrination. 


\section{N O T E S}

1 This hypothesis is also called the "nurture hypothesis", "learning effect", "learning hypothesis", "treatment effect", "training effect", and "socialization hypothesis" (Carter \& Irons, 1993; Cipriani, Lubian \& Zago, 2009; Gandal et al., 2005; Gerlach, 2017; Goossens \& Méon, 2015; Haucap \& Müller, 2014; Hummel et al., 2016; Ifcher \& Zarghamee, 2018; Kaiser et al. 2018; Laband \& Beil, 1999; Ng, 1988).

2 Without communication, the defection rate for economics majors was $60.4 \%$ while for the non-economists this value was 20 percentage points lower. With communication, it dropped to $28.6 \%$ and $25.9 \%$ respectively (Frank, Gilovich \& Regan, 1993: 164-166). The role of communication for the level of voluntary contributions in the PGG was also conclusively demonstrated by $\mathrm{Hu}$ and Liu (2003), and Altenmeyer-Bartscher et al. (2017). It should be, however, noted that this positive correlation between comunication and rates of cooperation in non-cooperative games seems to evaporate with rising stakes (van den Assem, van Dolder \& Thaler, 2012).

3 The game was based on the following pattern: the first player might have split a given sum of money between the second player and herself, then the sum given to the second player was multiplied and the second player made a decision on how to split the multiplied money between the first player and herself.

${ }^{4}$ Besides the normative version, there were also positive and control options, reading of which did not exert such an influence on respondents' choices as the normative one.

5 The role of culture on results of playing the Ultimatum and the Prisoner's Dilemma games has been confirmed in a comprehensive empirical study by Henrich et al. (2005). In the context of differences between economics and non-economics students' cooperativeness the influence of culture was captured by Dzionek-Kozlowska and Rehman (2017a; 2017b).

6 Yezer, Goldfarb and Poppen (1996) somewhat surprisingly interpreted that result as an sign of students' cooperativeness, not as an indicator of their honesty.

7 The course was coordinated by the same lecturer for both groups.

${ }^{8}$ In the academic year of $2020 / 2021$ all the classes were organised in this way because of the COVID-19 pandemic.

9 Five PLN is an equivalent of approx. 0.9 EUR.

10 In the AEA, there were only three levels of relatively similar membership rates $(50,60$ and 70 USD), whereas in the APSA there were six rates ranging from 34 USD to 180 USD, and in the ASA, there were five rates ranging from 65 USD to 180 USD (Laband \& Beil, 1999: 95).

\section{R E F E R E N C E S}

Ahmed, A. (2008). Can education affect pro-social behavior? International Journal of Social Economics, 35(4), 298-307. http://dx.doi.org/10.1108/03068290810 854565

Altenmeyer-Bartscher, M., Bershadskyy, D., Schreck, P. \& Timme, F. (2017). Endogenous institution formation in public good games: The effect of economic education. IWH Discussion Papers, No. 29/2017. 
Educated or Indoctrinated? Remarks on the Influence of Economic...

van den Assem, M. J., van Dolder, D. \& Thaler, R. H. (2012). Split of steal? Cooperative behavior when the stakes are large. Management Science, 58(1), 2-20. http://dx.doi.org/10.1287/mnsc.1110.1413

Bauman, Y. \& Rose, E. (2011). Selection or indoctrination: Why do economics students donate less than the rest? Journal of Economic Behavior 85 Organization, 79(3), 318-327. http://dx.doi.org/10.1016/j.jebo.2011.02.010

Cadsby, C. B. \& Maynes, E. (1998). Choosing between a socially efficient and freeriding equilibrium: Nurses versus economics and business students. Journal of Economic Behavior \& Orgnization, 37(2), 183-192.

Cason, T. N., Saijo, T. \& Yamato, T. (2002). Voluntary participation and spite in public good provision experiments: An international comparison. Experimental Economics, 5, 133-153.

Cipriani, G. P., Lubian, D. \& Zago, A. (2009). Natural born economists? Journal of Economic Psychology, 30(3), 455-468. http://dx.doi.org/10.1016/j.joep. 2008.10.001

Dasgupta, U. \& Menon, A. (2011). Trust and trustworthiness among Economics Majors. Economics Bulletin, 31(4), 2799-2815.

Davis, J. R. \& Welton, R. E. (1991). Professional ethics: Business students' perceptions. Journal of Business Ethics, 10, 451-463.

Delgado, C., Venkatesh, M., Branco, M. C. \& Silva T. (2020). Ethics, responsibility and sustainability orientation among economics and management masters' students. International Journal of Sustainability in Higher Education, 21(2), 181-199.

Dzionek-Kozlowska, J. \& Rehman, S. N. (2017a). Attitudes of economics and sociology students towards cooperation: A cross-cultural study. Economics 8 Sociology, 10(4), 124-136. https://doi.org/10.14254/2071-789X.2017/10-4/10

Dzionek-Kozlowska, J. \& Rehman, S. N. (2017b). Indoctrination, preselection or culture? Economic education and attitudes towards cooperation. Gospodarka Narodowa. The Polish Journal of Economics, 292(6), 57-77. https://doi.org/ $10.33119 / \mathrm{GN} / 100739$

Dzionek-Kozlowska, J. \& Rehman, S. N. (2019). Career choices and moral choices. Changing tracks in the Trolley Problem. Studies in Logic, Grammar and Rhetoric, 59(72), 177-189. https://doi.org/10.2478/slgr-2019-0036

Erikson, E. H. (1950). Childhood and society. New York: Norton.

Frank, R. H., Gilovich, T. \& Regan, D. T. (1993). Does studying economics inhibit cooperation? Journal of Economic Perspectives, 7(2), 159-171.

Frank, B. \& Schulze, G. G. (2000). Does economics make citizens corrupt? Journal of Economic Behavior \& Organization, 43(1), 101-113.

Gandal, N., Roccas, S., Sagiv, L. \& Wrzesniewski, A. (2005). Personal value priorities of economists. Human Relations, 58(10), 1227-1252. 
Gerlach, P. (2017). The games economists play: Why economics students behave more selfishly than other students. PloS ONE, 12(9), e0183814. https://doi.org/10.1371/journal.pone.0183814

Goossens, A. \& Méon, P.-G. (2015). The belief that market transactions are mutually beneficial: A comparison of the views of students in economics and other disciplines. Journal of Economic Education, 46(2), 121-134. https:// doi.org/10.1080/00220485.2014.991482

Haucap, J. \& Müller, A. (2014). Why are economists so different? Nature, nurture, and gender effects in a simple trust game. Dusseldorf Institute for Competition Economics Discussion Paper No. 136.

Henrich, J., Boyd, R., Bowles, S., Camerer, C., Fehr, E., Gintis, H., McElreath, R., Alvard, M., Barr, A., Ensminger, J., Smith-Henrich, N., Hill, K., GilWhite, F., Gurven, M., Marlowe, F. W., Patton, J. Q. \& Tracer, D. (2005). "Economic man" in cross-cultural perspective: Behavioral experiments in 15 small-scale societies. Behavioral and Brain Sciences, 28(6), 795815 .

Hu, Y.-A. \& Liu, D.-Y. (2003). Altruism versus egoism in human behavior of mixed motives. American Journal of Economics and Sociology, 62(4), 677-705.

Hummel, K., Pfaff, D. \& Rost, K. (2018). Does economics and business education wash away moral judgement competence? Journal of Business Ethics, 150, 559-577. https://doi.org/10.1007/s10551-016-3142-6

Ifcher, J. \& Zarghamee, H. (2018). The rapid evolution of homo economicus: Brief exposure to neoclassical assumptions increases self-interested behavior. Journal of Behavioral and Experimental Economics, 75, 55-65. https://doi.org/ 10.1016/j.socec.2018.04.012

Iida, Y. \& Oda, S. H. (2011). Does economics education make bad citizens? The effect of economics education in Japan. Journal of Education for Business, $86,234-239$.

James, T., Soroka, L. \& Benjafield, J. G. (2001). Are economists rational, or just different? Social Behavior and Personality, 29(4), 359-364.

Kaiser, J. P., Pedersen, K. S. \& Koch, A. K. (2018). Do economists punish less? Games, 9(4). https://doi.org/10.3390/g9040075

Kahneman, D., Knetsch, J. L. \& Thaler, R. H. (1986). Fairness and the assumptions of economics. Journal of Business, 59(4), S285-S300.

Krick, A., Tresp, S., Vatter, M., Ludwig, A., Wihlenda, M. \& Rettenberger, M. (2016). The relationships between the Dark Triad, the Moral Judgment Level, and the Students' disciplinary choice self-selection, indoctrination, or both? Journal of Individual Differences, 37(1), 24-30.

Laband, D. N. \& Beil, R. O. (1999). Are economists more selfish than other 'social' scientists? Public Choice, 100, 85-101.

Lanteri, A. \& Rizzello, S. (2007). Ought (only) economists to defect? Stereotypes, identity, and the prisoner dilemma. QuaderniSEMeQ 21/2007. 
Educated or Indoctrinated? Remarks on the Influence of Economic...

Marshall, A. (1920 [1890]). Principles of Economics. 8th Edition. London: Macmillan, Library of Economics and Liberty.

Marwell, G. \& Ames, R. E. (1981). Economists free ride, does anyone else? Experiments on the provision of public goods, IV. Journal of Public Economics, 15(3), 295-310.

Mertins, V. \& Warning, S. (2014). Greedy and selfish? Differences in fairness preferences of prospective lawyers and managers. Zeitschrift für Personalforschung, 28(4), 410-431.

Neubaum, D. O., Pagell, M., Drexler, J. A., McKee-Ryan, F. M. \& Larson, E. (2009). Business education and its relationship to student personal moral philosophies and attitudes toward profits: An empirical response to critics. Academy of Management Learning \& Education, 8(1), 9-24.

Ng, Y.-K. (1988). Economic efficiency versus egalitarian rights. Kyklos, 41(2), 215237.

O’Clock, P. \& Okleshen, M. (1993). A comparison of ethical perception of business and engineering majors. Journal of Business Ethics, 12, 677-687.

Seguino, S., Stevens, T. \& Lutz, M. (1996). Gender and cooperative behavior: Economic Man rides alone. Feminist Economics, 2(1), 1-21.

Tse, A. C. B., \& Au, A. K. M. (1997). Are New Zealand business students more unethical than non-business students? Journal of Business Ethics, 16, 445450.

Wang, L., Malhotra, D. \& Murnighan, J. K. (2011). Economic education and greed. Academy of Management Learning \& Education, 10(4), 643-660. http://dx.doi.org/10.5465/amle.2009.0185

Xin, Z. \& Liu, G. (2013). Homo Economicus belief inhibits trust. PLoS ONE, 8(10), e76671. http://dx.doi.org/10.1371/journal.pone.0076671

Yezer, A. M., Goldfarb, R. S. \& Poppen, P. J. (1996). Does studying economics discourage cooperation? Watch what we do, not what we way or how we play. Journal of Economic Perspectives, 10(1), 177-186. 